\title{
EDUCAÇÃO SEXUAL EM UMA ESCOLA: DA REPRODUÇÃO À PREVENÇÃO
}

\author{
HELENA ALTMANN
}

Professora da Faculdade de Educação Física da Universidade Estadual de Campinas altmann@fef.unicamp.br

\begin{abstract}
RESUMO
Este artigo é baseado em dados de pesquisa etnográfica desenvolvida entre agosto de 2002 e julho de 2003 em uma escola municipal da cidade do Rio de Janeiro, onde foram feitas observações e entrevistas. A educação sexual era realizada na disciplina de Ciências e dentro do Núcleo de Adolescentes Multiplicadores. Contraditoriamente, ao desenvolver a educação sexual a partir do tema reprodução, esta acabava sendo enfatizada, quando é justamente a ocorrência dela entre adolescentes que diversas políticas públicas querem evitar. Além do processo reprodutivo em si e dos modos de preveni-lo, a escola ensinava sobre a precocidade da gravidez na adolescência, apresentando ideais de maternidade e paternidade. As intervenções escolares buscavam desenvolver nos(as) adolescentes um sentido de "responsabilidade" em torno das relações sexuais, buscando mudar ou adequar os dispositivos que estruturam os comportamentos preventivos. No entanto, as informações sobre métodos anticoncepcionais, não raro, estavam ligadas ao mundo adulto, permanecendo distante dos adolescentes e sugerindo não reconhecimento da sexualidade adolescente.
\end{abstract}

EDUCAÇÃO SEXUAL - SEXUALIDADE - GRAVIDEZ - ESCOLAS

\section{ABSTRACT}

CASE STUDY ON SEXUAL EDUCATION: FROM REPRODUCTION TO PREVENTION. This article is based on data on sexual education from an ethnographic research carried between August 2002 and July 2003 in a public school in the city of Rio de Janeiro. Sex education was offered in Science courses provided by the Center of Adolescent Educators. The focus on reproduction matters contradictorily entice students to the subject of pregnancy which public policies wished to avoid. The course aimed at instigate a sense of responsibility about sexual relations. However information on contraceptive methods was usually related to adult s matters and remained distant from youth's anxieties thus not acknowledging adolescent sexuality. SEX EDUCATION - SEXUALITY - PREGNANCY - SCHOOL 
Este artigo analisa a educação sexual em uma escola no que se refere a um dos seus principais temas: a gravidez. Tal assunto era abordado na escola pesquisada sob duas perspectivas. Por um lado, estava em pauta o sistema reprodutivo e as diversas etapas do seu ciclo. De outro, adotando uma concepção de inadequação entre gravidez e adolescência, trabalhavam-se estratégias de prevenção.

Para refletir sobre esse assunto, são analisados dados de uma pesquisa etnográfica realizada em uma escola municipal de ensino fundamental $\left(5^{\mathrm{a}}\right.$ a $8^{a}$ séries), situada na Zona Sul da cidade do Rio de Janeiro'. O trabalho de campo foi desenvolvido entre agosto de 2002 e julho de 2003. A escola tinha em torno de 360 alunos/as matriculados/as, oriundos predominantemente de favelas da região.

Durante um ano, foram feitas observações de aulas de turmas de $7^{a}$ série do ensino fundamental, de reuniões do Núcleo de Adolescentes Multiplicadores - NAM -, reuniões de professores/as e outros eventos promovidos pela escola. Foram assistidas a aulas de Português, Matemática, Geografia, História, Educação Física, Artes Plásticas, Inglês e Ciências - principal espaço em que se falava sobre sexualidade.

Naquela época, o NAM era o principal projeto de educação sexual na rede municipal de ensino do Rio de Janeiro. Fora de seu horário de aula, alunos/ as reuniam-se sob a coordenação de uma professora ou professor para tratar assuntos ligados à adolescência, sexualidade, drogas, entre outros. A proposta era de que esses adolescentes multiplicassem as informações recebidas dentro de suas escolas e na comunidade. Esse projeto estava ligado ao Núcleo de Educação Ambiental e Saúde da Secretaria Municipal de Educação - SME. Cabe mencionar que ele atingia um número bastante restrito de estudantes, pois, em 2002, das 1.036 escolas municipais do Rio de Janeiro, apenas 63 contavam com um núcleo. Além disso, nem todos estudantes dessas escolas participavam das atividades desenvolvidas. Na escola pesquisada, o NAM era coordenado por uma professora de Ciências e o grupo chegou a contar com até 15 participantes².

I. Esta pesquisa contou com os financiamentos inicialmente do Conselho Nacional de Desenvolvimento Científico e Tecnológico - CNPq - e posteriormente da Fundação de Amparo à Pesquisa do Estado do Rio de Janeiro - Faperj -, tendo resultado em tese de doutorado (Altmann, 2005).

2. Sobre os NAMs e a formação dos profissionais de educação sexual, vide a pesquisa de Rodrigo Rosistolato (2007). 
Educação sexual em uma escola...

Além das observações, foram feitas entrevistas com estudantes, professores/as de diferentes disciplinas, membros da direção e professoras de Ciências de outras escolas. Foram realizadas 23 entrevistas, das quais $13 \mathrm{com} 30$ alunas e alunos divididos em pequenos grupos. As entrevistas com os professores foram feitas individualmente.

Entre os/as entrevistados/as, havia participantes do NAM, bem como pessoas que nunca tinham participado e outras que tinham deixado de participar. A maioria dos entrevistados cursava a $7^{\mathrm{a}}$ série, no entanto, alguns estavam na sexta e outros na oitava. Foram entrevistados 20 meninas e 10 meninos. Os entrevistados tinham entre 12 e 15 anos, sendo sua idade mediana de 14 anos. Os nomes das pessoas entrevistadas são fictícios, tendo sido escolhidos por elas próprias por ocasião das entrevistas.

\section{SOBRE A INADEQUAÇÃO SOCIAL ENTRE GRAVIDEZ E ADOLESCÊNCIA}

Durante uma entrevista com dois garotos, um deles contou que já conversara com o pai e a mãe sobre questões ligadas à sexualidade. Ao serem então questionados sobre o que aprenderam de diferente no colégio em relação ao que fora falado em casa, Marcos ( 14 anos) respondeu que, na escola, aprendeu sobre "gravidez precoce e doenças". Felipe ( 14 anos) concordou e Marcos continuou: "Eu não sabia que tinha gravidez precoce!", e disse que só sabia que existia gravidez. Ao ser questionado sobre o que diferencia uma da outra, explicou: "Para mim, a pessoa que planeja o filho e aceita o filho, é a gravidez normal. E a gravidez precoce é a daquela pessoa que rejeita o filho". Contou o caso de uma vizinha de nove anos que teria engravidado por opção. Questionado se, nesse caso em que ela queria engravidar, a gravidez era precoce ou não, disse que, "se ela queria, não era precoce". Seu colega, percebendo a confusão, afirmou que "tem a idade também".

Ao explicar, Marcos mistura os termos precoce e indesejada, os quais foram aprendidos na escola, pois antes ele não sabia adjetivar a gravidez dessa maneira. As expressões precoce e indesejada eram recorrentemente utilizadas na escola, mas, a partir de uma certa época, a professora mencionou preferir empregar o termo "gravidez não planejada", por reconhecer que, muitas vezes, mesmo na adolescência, há o desejo de engravidar. Independentemente 
do termo adotado, suas utilizações atribuem características especiais a uma gravidez nessa faixa etária, demonstrando que essa não é considerada a época mais adequada para gerar um filho.

Essa questão surgiu em uma conversa em sala de aula. A professora perguntou à turma por que uma gravidez "precisa" ser planejada. Um menino respondeu que "se a família estivesse em uma situação crítica, a criança poderia ter problemas". Outros argumentaram: "para a criança não vir na hora errada", "para primeiro ter condições de sustentar o filho". Além disso, a professora complementou explicando que adolescentes têm relações passageiras, "gostam de uma pessoa e após algum tempo não gostam mais", de modo que esse não é um bom momento para se ter um filho. A conversa deixa a mensagem de que um filho deve ser planejado por um casal que viva uma relação estável, num momento da vida em que tenham condições financeiras e pessoais para sustentar a criança.

Assim, uma gravidez nessa faixa etária parece nunca ser chamada simplesmente de gravidez. Ao contrário, ela é recorrentemente adjetivada de, por exemplo, "na adolescência", "precoce", "indesejada", "não planejada", "de risco" ou "inesperada". Cabe observar que, sendo a idade adulta o período da vida considerado ideal para gerar um filho, não se fala, por exemplo, em gravidez na idade adulta ou "gravidez na adultescência" - expressão que nem mesmo consta nos dicionários. É necessário nomear apenas o que foge à norma.

A bibliografia na área tem apontado uma série de problemas na utilização desses termos. Sabe-se, como a própria professora da escola mencionou, que uma gravidez nessa faixa etária é frequentemente desejada. O termo "não planejada", por sua vez, implica uma capacidade de projetar o futuro, o que é uma disposição socialmente adquirida, nem sempre presente. De modo semelhante, o termo precoce, indica que esta faixa etária não é considerada ideal para uma gravidez, a qual deve ser postergada. Desse modo, um outro termo que independe de faixa etária tem sido atualmente utilizado: "gravidez não prevista" (Bajos, Ferrand, Hassaun, 2002).

Historicamente esses modos de classificar a gravidez nem sempre estiveram presentes. Já houve épocas em que as mulheres engravidavam mais cedo, numa idade que hoje seria considerada "precoce". Assim, a gravidez não pode ser vista como uma realidade biológica imutável, mas antes como resultado de um processo social e cultural. Transformações sociais fizeram surgir novas 
Educação sexual em uma escola...

imagens de mulher, de juventude e de infância que contribuem para adiar a idade socialmente aceita para uma primeira gravidez.

Desse modo, uma das primeiras questões a ser problematizada é a forma genérica de se referir à adolescência. Desconsidera-se que as maneiras de entrar na vida adulta não são homogêneas, variando segundo uma série de fatores, entre outros, origem social e gênero. A partir de uma ampla pesquisa desenvolvida em três capitais brasileiras, Maria Luíza Heilborn et. al. (2002) mostram o caráter indissociável da articulação entre classe social e gênero na compreensão do fenômeno da gravidez na adolescência. As jovens de camadas médias modificam seus projetos e trajetórias escolares que, até então, processavam-se de modo linear. $\bigcirc$ mesmo não ocorre entre as jovens das camadas populares, onde a irregularidade das carreiras escolares independe da maternidade. Entre os homens jovens não há mudanças significativas, pois os estratos médios não interrompem seus projetos e percursos educacionais, enquanto os dos grupos populares ingressam precocemente no mercado de trabalho, independentemente da experiência de paternidade.

Ao estudar as gravidezes na adolescência na França, Charlotte Le Van (1998) mostra que, se a gravidez em idades jovens não é um fenômeno inédito em si mesmo, as recentes evoluções sociais e culturais contribuíram para fazê-la emergir como um problema social novo. Para a autora, a expansão e o prolongamento do ensino, assim como a inserção da mulher no mercado de trabalho, contribuíram para um retardamento da gravidez e da constituição da família. A imagem social da criança também se modificou: despojada progressivamente de seu valor econômico e social, ela aparece, antes de tudo, como uma gratificação. Os futuros pais devem escolher o momento propício para procriar, quando o filho não possa mais criar obstáculos para suas realizações pessoais e quando sejam suscetíveis a lhe dar as melhores condições possíveis de vida. A exigência de uma paternidade e maternidade "inteligentes" implica que a criança desejada chegue no momento em que o casal possa lhe oferecer o espaço e a estabilidade necessários.

Outrossim, o aparecimento de novas expectativas sociais em relação à juventude é um dos elementos que, segundo Heilborn et al. (2002), tornam o fenômeno consideravelmente mais visível. "A gravidez na adolescência desponta como um desperdício de oportunidades, como uma subordinação - precoce - a um papel do qual, durante tantos anos as mulheres, tentaram se desvencilhar" 
(p. 18). Outro elemento é o aumento, ao longo das duas últimas décadas, da proporção de gravidezes e de nascimentos que na juventude ocorrem fora de uma união. A considerada "ilegitimidade" dessa gravidez também contribui para transformá-la em problema social.

Demanda-se da mulher uma "dupla gestão": do número de filhos e do momento adequado para a maternidade. Considerando uma série de fatores, ela deve escolher o melhor momento para ter um filho e número de filhos que pretende ter. Essa exigência de programação pressupõe uma capacidade social de dirigir sua própria vida, da qual nem todas as mulheres são dotadas (Bajos, Ferrand, Hassaun, 2002).

Se a maternidade não pode ser vista como um fenômeno natural em si mesmo, o equivalente pode ser dito em relação à adolescência ou à juventude. $\bigcirc$ que significa ser adolescente? Onde se situam as fronteiras entre adolescência, juventude e idade adulta? De um ponto de vista sociológico, essas perguntas não poderiam ser respondidas de modo essencialista ou funcionalista, pois as noções de adolescência e juventude são invenções sociais, historicamente situadas (Galland, 200 I). A noção de juventude se constrói socialmente e sua descoberta, seguida da promoção da adolescência, não são tão antigas quanto muitas vezes imaginamos. Foi a partir do século XVII que a passagem da infância para a idade adulta foi se prolongando, e deixou de ser uma transição curta, para exigir cada vez mais investimentos, principalmente em termos de educação.

Galland (200 I) destaca alguns fatores que influenciaram neste processo. Apesar de seu estudo ter sido desenvolvido na França, suas análises são úteis para pensarmos o caso brasileiro. A promoção da infância e da adolescência está ligada ao fato de a burguesia ter modificado progressivamente sua atitude em relação aos seus descendentes. A baixa da fecundidade permitiu aos pais dar mais atenção aos filhos. A educação extra-familiar, visando assegurar o sucesso no estabelecimento social e profissional, foi se impondo progressivamente, e passou a conferir um papel social novo a uma nova idade da vida: a adolescência. Na Europa, a descoberta da infância e da adolescência como idades a serem educadas, inicia-se no fim do século XVII e triunfa definitivamente no século XIX.

Mesmo assim, o autor destaca a necessidade de relativizar a influência real da educação na organização das idades e entrada na idade adulta, pois, 
Educação sexual em uma escola...

mesmo no século XIX, ainda é mais a "ideia" de educação do que a educação ela mesma que se desenvolve. A educação permanecia ainda restrita às elites. Além disso, a juventude não existia no meio operário, onde a inserção social permanecia vinculada à família e direcionada muito cedo ao trabalho. A família operária, no início da industrialização e da urbanização, esteve marcada pela instabilidade de emprego e de moradia. Sua condição social e econômica impedia que construísse um projeto de vida viável para os filhos, o futuro incerto e a falta de planejamento faziam com que não controlasse a fecundidade.

Atualmente, ainda segundo Galland (1996), o período de indeterminação próprio da adolescência ultrapassa o tempo escolar, estendendo-se à fase de inserção profissional, ainda mais longa e mais incerta que antigamente. Além disso, as modalidades de entrada na vida adulta permanecem tributárias de modelos culturais em que as variáveis de origem social e de sexo pesam.

Questão semelhante também é apontada em pesquisas desenvolvidas no Brasil, onde os percursos escolares têm-se alongado e a independência econômica e residencial juvenil se efetiva mais tardiamente. Observa-se, segundo Elaine Brandão (2004), um descompasso entre a instalação de relações afetivo-sexuais, geradoras de autonomia pessoal, e as condições sociais que possibilitam sua independência.

\section{GRAVIDEZ NA ADOLESCÊNCIA COMO UM PROBLEMA DEMOGRÁFICO}

Outro modo de tratar a gravidez nesta faixa etária é como um "problema demográfico". Essa abordagem se sustenta em dados estatísticos que, por um lado, demonstram a redução das taxas totais de fecundidade no Brasil, entre 1960 e 2000, de 6,3 para 2,3 filhos por mulher, enquanto, por outro, mostram um aumento das taxas entre jovens de 15 a 19 anos (IBGE, 2002, 2002a).

Segundo Michel Foucault ( 1987), a partir do século XVIII a "população" torna-se um problema econômico e político. No cerne dessa questão está o sexo, sendo necessário analisar a taxa de natalidade, a idade do casamento, os nascimentos legítimos e ilegítimos, a precocidade e a frequência das relações sexuais, a maneira de torná-las fecundas ou estéreis, o efeito do celibato e das interdições, a incidência das práticas contraceptivas. É a primeira vez que, de maneira mais constante, uma sociedade afirma que seu futuro e sua fortuna 
estão ligados à maneira como cada um vive seu sexo. A administração do sexo torna-se um importante "princípio regulador" da população, dando margem a medidas massivas, a estimativas estatísticas, a intervenções que visam a todo o corpo social ou grupos tomados globalmente.

Apesar de a questão populacional não ser novidade, é com o grande crescimento demográfico do ocidente europeu durante o século XVIII que a necessidade de coordená-lo e de integrá-lo ao desenvolvimento do aparelho de produção, e a urgência de controlá-lo por mecanismos de poder mais adequados e mais rigorosos fazem aparecer a "população". A este problema passam a ser aplicados novos tipos de saber: a demografia, observações sobre o controle de epidemias, inquéritos sobre as amas de leite e as condições de aleitamento. Além disso, estabelecem-se aparelhos de poder que permitem não somente a observação, mas também a intervenção direta. Assim, não se trata apenas de um problema teórico, mas de um objeto de vigilância, análise, intervenções, operações transformadoras etc. Foucault (1994) afirma que, a partir desse momento, aparece algo que se pode chamar de poder sobre a vida.

Tal fenômeno é contemporâneo à formação dos estados nacionais modernos, que se veem diante da necessidade de conhecer seu território para avaliar como nele se repartem seus habitantes. Para tal, é necessário examinar os índices de crescimento demográfico, os fluxos migratórios, entre outros. No entanto, torna-se, sobretudo, necessário conhecer as taxas de mortalidade e de reprodução, os fenômenos epidêmicos e endêmicos e tudo o que concorre para determinar as condições de vida das populações, de modo a fornecer à administração os instrumentos apropriados que permitem uma intervenção eficaz de modo a reforçar a potência dos estados. Tal inflexão histórica marca a entrada da vida no domínio da política e, portanto, tal como nomeou Foucault, o nascimento da biopolítica, quer dizer, a entrada da vida e seus mecanismos no domínio dos cálculos explícitos que faz dos poderes e saberes agentes de transformação da vida humana. É assim que o ser humano, como espécie, torna-se algo que entra em jogo nas estratégias políticas das sociedades ocidentais (Bertani, 200I).

Os problemas da população e de sua gestão continuam atuais. $O$ que pretendo aqui demonstrar é que as preocupações em torno da gravidez na adolescência estão em grande parte relacionadas a esta questão.

As mudanças nos dados estatísticos dos dois últimos censos - 1991 e 2000 - foram analisadas por Elza Berquó e Suzana Cavenaghi (2004), que 
Educação sexual em uma escola...

mostram, a partir da tabela reproduzida abaixo, que, devido ao declínio da fecundidade específica em idades mais avançadas do ciclo reprodutivo e, em menor intensidade, devido ao acréscimo desta no grupo mais jovem, vem aumentando a importância relativa do grupo etário mais jovem no cômputo da taxa de fecundidade total. Em 2000, a fecundidade das jovens de 15 a 19 anos respondeu a $20 \%$ do número total de filhos tidos pelas mulheres ao longo de todo o período reprodutivo, enquanto em 1980 esse valor era de $9 \%$ e em 1991, |4\%. Conforme aparece na tabela a seguir, o grupo etário de 15 a 19 anos foi o único a ter uma variação positiva na taxa de fecundidade, de 25,4\%, enquanto em todos os outros essa variação foi negativa.

TABELA I

VARIAÇÃO DAS TAXAS ESPECÍFICAS DE FECUNDIDADE POR IDADE. BRASIL, I99| E 2000

\begin{tabular}{|c|c|c|c|}
\hline Grupos de idade & $199 \mid$ & 2000 & Variação (\%) \\
\hline $15-19$ & 0.0745 & 0.0938 & 25.4 \\
\hline $20-24$ & 0.1450 & 0.1356 & -6.5 \\
\hline $25-29$ & 0.1357 & 0.1145 & -15.6 \\
\hline $30-34$ & 0.0943 & 0.0748 & -20.7 \\
\hline $35-39$ & 0.0561 & 0.0404 & -28.0 \\
\hline $40-44$ & 0.0254 & 0.0134 & -47.4 \\
\hline $45-59$ & 0.0059 & 0.0022 & -63.3 \\
\hline
\end{tabular}

Fonte: IBGE, Censos Demográficos de 199I e 2000 (apud Berquó, Cavenaghi, 2004, p.5).

As autoras destacam que o aumento da fecundidade entre adolescentes e mulheres muito jovens é um tema que merece bastante atenção, pois se sabe pouco sobre suas causas e reais consequências para as mulheres. A distribuição dos nascimentos entre jovens e adolescentes, por idade simples da mãe, mostra que os aumentos ocorreram entre aquelas com 15, 16 e 17 anos, caindo a participação relativa, embora majoritária, nas idades de 19 e 20 anos. Os dois últimos censos mostram ainda que o aumento de $25 \%$ da fecundidade entre jovens e adolescentes não foi uniforme em todas as camadas socioeconômicas: foi mais expressivo entre as jovens menos escolarizadas e as mais pobres. Foi mais intenso nas áreas urbanas, embora o aumento tenha ocorrido também no meio rural (Berquó, Cavenaghi, 2004). Diante desse quadro, as pesquisadoras alertam: 
$\bigcirc$ aumento de fecundidade em idades jovens também merece atenção das políticas públicas, pois pode estar refletindo não somente um rejuvenescimento deliberado da fecundidade, mas uma falta de acesso a meios contraceptivos adequados, devido a mudanças no comportamento das práticas sexuais, nem sempre acompanhadas por mudanças de atitudes dentro das famílias e ajustes nos sistemas de atenção básica à saúde dos jovens. Desta forma, o mapeamento desses processos é importante para o desenho de programas e ações adequadas. (Berquó, Cavenagui, 2004, p.8)

\section{MOMENTO E SITUAÇÃO IDEAIS}

$\mathrm{Na}$ escola pesquisada, por meio de uma dinâmica desenvolvida em agosto de 2002, por ocasião do Dia dos Pais, certa concepção ideal de paternidade e maternidade voltou a aparecer. Inicialmente ela foi realizada com os/ as integrantes do NAM e, posteriormente, com algumas turmas do turno da manhã, que foram convidadas para ir ao laboratório para uma "multiplicação".

A dinâmica fora sugerida pela Secretaria Municipal de Educação, mais precisamente, pelo Núcleo de Educação Ambiental e Saúde através de uma publicação bimestral chamada Ambiente em Rede (2002). A dinâmica também fora desenvolvida durante uma reunião de coordenadores de NAMs, que, nesta ocasião, contou com a participação de alguns/mas estudantes. Este jornalzinho informa sobre a criação do Decreto n.21.649, de 27 de junho de 2002, que institui a segunda semana de agosto como a Semana de Valorização da Paternidade. Naquele ano, o jornal propunha para escolas e unidades de saúde, uma reflexão sobre a pergunta "O que é ser pai?". Nesse sentido, algumas dinâmicas eram propostas em torno dessa temática.

A primeira delas, destinada a estudantes de $5^{\mathrm{a}}$ a $8^{\mathrm{a}}$ série, era intitulada "Um recado para você: você vai ser pai!". O objetivo era "explorar a decisão sobre o ato de assumir a paternidade: suas implicações afetivas e sociais". A dinâmica consistia no seguinte. Formavam-se três grupos e cada um deles recebia um bilhete com uma situação que deveria ser interpretada pelo grupo. As situações eram as seguintes:

I. pessoa com relacionamento duradouro, cuja gravidez acontece sem planejamento; 
Educação sexual em uma escola...

2. pessoas que se encontram apenas uma noite, que possuem amigos em comum e cuja gravidez não era esperada;

3. casal que deseja ter um filho e que recebe um resultado positivo no laboratório. (Ambiente em Rede, 2002, p.3)

O informativo também sugeria as seguintes perguntas para a discussão, as quais foram utilizadas pela professora:

- Se o rapaz assumir a paternidade, o que vai precisar fazer?

- Se o rapaz não assumir a paternidade, o que a moça pode fazer?

- O que é assumir a paternidade?

- Eles devem casar?

- Como se sente o homem quando recebe a notícia de que sua parceira está grávida?

- Como os jovens percebem a mulher que tem relações sexuais com um homem, no primeiro encontro?

- Qual a idade de cada um dos casais?

- Existe diferença entre a gravidez que acontece numa relação duradoura e uma gravidez que acontece numa transa eventual?

- Se a mulher quisesse interromper a gravidez e você quisesse ter o filho, o que você faria?

- E se você quisesse interromper a gravidez e a mulher quisesse ter o filho, o que você faria? (Ambiente em Rede, 2002, p.3)

Algumas questões merecem destaque em relação aos debates em torno dessas três encenações. Expressam uma postura contrária em relação ao aborto, posição também partilhada pela professora. "Só se for carrasca para abortar!", exclamou alguém. Se havia opiniões contrárias a essa, elas não foram expressas, o que é compreensível diante da ilegalidade do aborto no Brasil. Nas entrevistas, os/as estudantes também se manifestavam contrários, no entanto, contavam sobre pessoas próximas que já tinham abortado, como amigas, vizinhas e mães.

Em relação às situações analisadas, era consenso de que um casal não deveria casar como consequência de uma gravidez. No máximo, se quisessem e gostassem um do outro, deveriam morar juntos e avaliar se a relação teria ou não continuidade. 
Transparece no debate, assim como nas entrevistas, a concepção dos adolescentes de que a responsabilidade maior pela prevenção da gravidez é da menina. Por serem elas que engravidam, o assunto gravidez acaba sendo considerado de maior interesse e responsabilidade das mulheres. Para os/as estudantes, a menina é mais responsável pela gravidez do que o menino, "porque é no corpo dela, ela que vai ficar grávida" (Laura, I 4 anos). A esse respeito, Felipe ( 14 anos) afirmou: "Eu acho que pode ser os dois: o garoto para não pegar doença e a garota para não pegar doença e não ter filho." Uma outra menina disse: "Eu acho que a responsabilidade da gravidez é dos dois. Eu não quis ter o filho sozinha, eu não ia querer ter o filho sozinha. Mas eu acho que é mais irresponsabilidade dela, sabendo que ela podia usar camisinha" (Júlia, 14 anos). Mesmo naquelas falas em que uma parcela de responsabilidade era atribuída ao menino, ela era menor do que a da menina: a responsabilidade é de ambos, mas a irresponsabilidade é da menina; ele deve usar um preservativo para não pegar doenças, ela, também, para não engravidar. Além disso, cabe também observar que grande parte desses adolescentes não convive com os pais. Essa falta de experiência paterna vivenciada na condição de filhos parece influenciar a desresponsabilização masculina pela paternidade.

A criação mediante um decreto-lei de uma Semana de Valorização da Paternidade e a implementação na escola de políticas educacionais, que incentivam a paternidade responsável, parecem ser respostas a desresponsabilização dos meninos, não só pela prevenção da gravidez, como pela responsabilidade de criar os filhos. É curioso notar que a escola colocava em ação uma prática de incentivo à responsabilidade paterna, enquanto o mesmo não era feito em relação à maternidade, nem mesmo por ocasião do Dia das Mães. Tal data não foi celebrada. É como se uma precisasse ser incentivada, enquanto a outra, freada.

Além disso, o impacto da gravidez também era visto como maior na vida da menina do que na do menino. Quando falavam sobre o que muda na vida de um garoto quando ele se torna pai, mencionaram que terá de trabalhar para sustentar a criança e que deve ajudar a garota - sendo companheiro, conversando, compreendendo-a. Para eles, a responsabilidade do menino com o filho é apenas financeira, nunca mencionam alguma necessidade em termos de cuidados em criar o bebê. Para a menina, a maternidade "muda tudo", faz com que ela "perca a sua juventude", pois seu corpo muda, ela sente as dores 
Educação sexual em uma escola...

do parto, tem de cuidar do bebê, não pode sair, precisa ser mais responsável, tem de deixar de estudar por algum tempo, entre outros ${ }^{3}$.

Retomando as três situações encenadas e o debate por elas desencadeado, cabe observar que a dinâmica parecia ter o objetivo central de apresentar uma situação ideal de maternidade e paternidade, qual seja, aquela de um casal com um relacionamento estável e duradouro que deseje e planeje um filho. As outras duas situações apresentam problemas, sendo mais condenada a segunda, quando um casal que pouco se conhece se defronta com a gravidez. Nesse caso, além da gravidez, foi ressaltado que teriam corrido risco de contrair alguma doença sexualmente transmissível - DST -, como por exemplo, Aids. A primeira situação, apesar de o relacionamento ser mais longo, também não é ideal, porque carece de planejamento, podendo criar problemas para o casal, que, nas encenações, era sempre de namorados. Mostra-se assim novamente que um filho ou filha deve vir dentro de uma relação estável, em um momento propício da relação, tendo sido planejado e desejado por um casal heterossexual. Destaca-se que para isso é preciso se prevenir, usando prioritariamente algum preservativo ou então algum outro método anticoncepcional.

\section{"SER PAI É..."}

No entanto, independentemente da situação em que a gravidez ocorra, o homem, ou nesse caso, o garoto, é conclamado a se responsabilizar pelo filho. Para isso, após a dinâmica supracitada, a professora solicitou que cada um escrevesse em uma folha de papel uma frase que definisse o que é ser pai. As frases, posteriormente afixadas num mural no corredor da escola, foram as seguintes:

Respostas de meninos:

Ter responsabilidade e assumir todos os seus atos.

3. Um estudo sobre as representações e os arranjos de jovens do sexo masculino, oriundos de camadas populares, em relação à gravidez ocorrida na adolescência mostrou que esses jovens interrompiam sua trajetória escolar em prol da profissional, mais por questões materiais do que em razão da gravidez em si. Segundo o estudo, está presente nesse universo um imperativo moral que incita o homem à busca pelo trabalho (Cabral, 2002). Sobre o impacto da gravidez nas trajetórias escolares e profissionais de adolescentes, vide também Heilborn et. al. (2002). 
Ser pai para mim é tudo de bom nesta vida porque pai é uma coisa muito interessante não só para mães, mas para todo mundo.

Como diz o ditado, pai não é aquele que cria, mas aquele que faz. Pai para mim não me diz nada, eu não tenho pai pra sentir esse gosto. Eu acho que é só isso.

Ser pai é um sentimento muito bom. Mas na maioria dos casos atrapalha a própria vida.

Ser pai novo sem quase nenhuma profissão é ter responsabilidade de gente grande, porque morando com os pais sendo sustentado pelos pais é muito difícil. Por isso é ter responsabilidade de gente grande, por isso quem quer ser pai pense primeiro, usem camisinha.

Ser pai não é apenas ser pai, é dar amor, carinho para a criança e assumir todas as responsabilidades e criar a criança para que quando ela cresça venha ser um grande homem de verdade.

Ser pai é assumir uma responsabilidade muito grande.

Respostas de meninas:

Ser pai é ser responsável, carinhoso, atencioso, consciente e antes de tudo amar mais que tudo esse ser que está trazendo ao mundo. Ser pai é ser um super-herói que protege, dá carinho, atenção, amor.

Ser pai é cuidar quando estiver doente, se preocupar quando demorar no passeio. Botar o filho em primeiro lugar, depois a namorada e o lazer. Comparecer às reuniões na escola. Ser pai é ser carinhoso, atencioso, compreensivo e responsável. Ser pai é... cuidar bem dos filhos, dar uma boa educação, fazer seu filho feliz, bem-humorado e ficar sempre com um sorriso estampado no rosto. É fazer e acontecer, ser carinhoso, responsável, dedicado e principalmente amado.

Ser pai é ser um homem mais responsável.

Resposta sem identificação:

Ser pai, não é apenas dar roupas, comida, casa para morar, ser pai é ser amigo, melhor amigo compartilhar em todos os momentos, entender o filho, interagir confiar, ensinar e acima de tudo respeitar em todos os sentidos.

Palavra recorrente nas definições é "responsabilidade". Ser pai é assumir uma grande responsabilidade, atribuída ao mundo adulto e que implicará sustentar financeiramente a criança e, além disso, dar carinho, atenção, amor, 
Educação sexual em uma escola...

ter preocupações, ser amigo, compartilhar momentos etc. Responsabilidades mais afetivas apareceram com maior intensidade nas frases das meninas. As frases dos meninos parecem dar mais importância à responsabilidade e às consequências disso para a vida pessoal. Um garoto chega a dizer que ser pai, na maioria das vezes, "atrapalha a própria vida".

Muitas das frases escritas expressam um ideal de paternidade, que era pregado não só pela escola, mas em outras instâncias sociais, como a mídia. A época em que essa dinâmica foi realizada - Dia dos Pais - é particularmente propícia para a vinculação dessas mensagens, por meio de comerciais que buscam vender produtos lembrando os filhos do companheirismo, do carinho etc. que receberam desde o nascimento.

Dando continuidade a essa dinâmica, foram elaborados cartazes para os quais se escolheram gravuras de revistas. Estas haviam sido selecionadas no encontro anterior. Uma delas vinha acompanhada com a seguinte manchete: "Meu pai é gay, minha mãe é lésbica". Ao ser recortada por uma garota, ela já provocou espanto de alguns colegas, que questionaram a professora se aquele recorte poderia ser utilizado. Ela simplesmente concordou, sem prolongar a discussão, e a imagem integrou a pilha das selecionadas. Ao confeccionarem os cartazes, "a mãe lésbica e o pai gay" ficaram de fora. Em baixo de cada imagem, foi escrita uma frase:

Ser pai é:

- ser legal, é ser atencioso, é ser responsável

- ser feliz

- dar proteção, se preocupar

- estar presente quando mais se precisa

- dar atenção, uma boa educação

- ser consciente que tem uma pequena "vida" para criar, educar, sustentar e principalmente amar

- saber ouvir

- é sempre mostrar o bom caminho

- ser companheiro, ser carinhoso, ser dedicado e ser bem humorado pelo mais simples que seja. 
De modo semelhante, o cartaz elaborado pelo outro grupo continha os seguintes dizeres:

- ser companheiro

- ser responsável

- ser feliz

- ser compreensivo

- ser amigo nas horas ruins ou boas

- é cuidar

- dar amor, proteger, brincar... e aceitar as opções próprias do seu filho(a), porém não esquecendo de participar de seu dia a dia

- dar carinho

De modo ainda mais intenso do que as frases escritas pelos/as estudantes, esses cartazes pregam um ideal de paternidade o qual se mostrava não ser parte da experiência de vida de grande parte desses/as adolescentes. A terceira frase transcrita, escrita por um garoto, é exemplar nesse sentido: "Como diz o ditado, pai não é aquele que cria, mas aquele que faz. Pai para mim não me diz nada, eu não tenho pai pra sentir esse gosto. Eu acho que é só isso." Ele recorre a um ditado, mas o reproduz ao contrário. Revela não ter tido a experiência de ser criado por um pai, motivo pelo qual não tem nada a dizer sobre o tema proposto.

Essa era a experiência de diversos estudantes naquela escola. As fichas cadastrais disponíveis na secretaria da escola mostravam que grande parte deles não convivia com o pai, residindo apenas com a mãe. Alguns conheciam, mas tinham pouco ou nenhum contato com o pai. Outros, nem mesmo tinham o nome do pai registrado na sua certidão de nascimento.

Também as discussões no NAM, uma delas suscitada a partir dessa própria dinâmica, corroboravam esses dados. Ao invés de uma relação romântica com o pai, reclamavam que ele era ausente, que abandonara a mãe, que não pagava pensão ou que o dinheiro não era suficiente, que não saíam juntos, entre outros. 
Educação sexual em uma escola...

\section{REPRODUÇÃO E ANTICONCEPÇÃO}

As dinâmicas descritas foram desenvolvidas no NAM. Em sala de aula, porém, a sexualidade, como tema de estudo ou de discussão, era abordada a partir dos livros didáticos, tendo como eixo central a reprodução. Ali, toda a ênfase era dada ao sistema reprodutor, à geração de uma nova vida, à gravidez, ao parto, enquanto informações sobre adolescência, métodos anticoncepcionais, Aids, DST apareciam como anexos. Assim, no livro utilizado pela escola, a relação sexual era sistemática e exclusivamente relacionada à reprodução. Não havia, por exemplo, imagens externas dos órgãos sexuais, a vulva não aparecia e tampouco era mencionada, assim como em nenhum lugar estavam escritas as palavras prazer, orgasmo, clitóris, homossexualidade, travesti, entre outras. $\bigcirc$ livro falava sobre órgãos sexuais, hormônios, fecundação, gravidez, em suma, a relação sexual era constantemente vinculada à sua função reprodutiva (Silva Junior, Sasson, Sanchez, 1997).

Parece haver uma contradição no trabalho desenvolvido pela escola. Por um lado, um dos objetivos da educação sexual é evitar a gravidez na adolescência. Esta justificativa consta dos Parâmetros Curriculares Nacionais (Brasil, 1998) e também foi expressa, direta ou indiretamente, por diversos docentes. Mais recentemente, em maio de 2007, o governo federal divulgou um novo programa de planejamento familiar que tem como principal medida baixar o custo da pílula anticoncepcional. Além disso, o programa "inclui a divulgação dos métodos anticoncepcionais nas escolas e nas TVs" (Beguoci, 2007). No entanto, quando se fala sobre sexo, toda ênfase recai justamente sobre fecundação, gestação e maternidade. Cabe, portanto, questionar se enfatizar a gestação e vincular reiteradamente a relação sexual à reprodução são as melhores estratégias quando se tem o objetivo de prevenir a gravidez entre jovens.

Outra questão é que, no livro didático, os métodos anticoncepcionais são recomendados a pessoas adultas, que optariam pelo planejamento familiar, de modo que os filhos tivessem suas necessidades básicas atendidas. O tema "O controle da natalidade" é introduzido com o seguinte parágrafo:

É sem sombra de dúvida muito importante que as crianças, numa família, tenham acesso a uma nutrição correta e a uma educação adequada crescendo de forma 
saudável, tanto física como mentalmente. Esse tipo de preocupação faz com que muitos adultos planejem o tamanho de sua família, para que as necessidades básicas dos filhos sejam atendidas. (Silva Junior, Sasson, Sanchez, 1997, p. 198 , grifos meus)

Logo a seguir, o autor cita diversos métodos anticoncepcionais, quais sejam, método da tabelinha, diafragma, dispositivos intra-uterinos, pílulas anticoncepcionais, preservativos (somente o masculino ${ }^{4}$ ), coito interrompido e esterilização. $\bigcirc$ único motivo que, no livro didático, justificaria a utilização de algum método anticoncepcional é o planejamento familiar para o controle do número de filhos. A possibilidade de optar por não tê-los não é cogitada, assim como sua utilização não é justificada pela associação do sexo ao prazer. Além disso, seu uso é relacionado ao mundo adulto e não a jovens. Essa associação distancia os métodos anticoncepcionais dos/as jovens, pois sua utilização é recomendada a casais adultos e não a jovens que namoram ou que "ficam" eventualmente com alguém. Essa questão também foi observada por Jane Felipe ( 1998 ) em relação a livros infantis, que não raro trazem conceitos distantes da realidade das crianças, sendo sexo e sexualidade vinculados à procriação e somente a pessoas casadas.

Essa abordagem distancia dos adolescentes os métodos anticoncepcionais, podendo dificultar seu acesso, uma vez que seu uso não parece legítimo nessa faixa etária. Em pesquisa desenvolvida na França, Sandrine Durand (2002) ressalta que o sentimento de não legitimidade da sexualidade entre adolescentes ou até de culpabilidade pode dificultar o acesso à contracepção. Ao contrário, uma diminuição da culpabilidade sexual elimina de forma significativa às hesitações das jovens em adotar atitudes contraceptivas positivas. A pesquisadora destaca a influência determinante do reconhecimento social da sexualidade adolescente na sua percepção de risco e de adoção de práticas preventivas, tanto no que se refere à gravidez quanto à Aids, o que leva a uma relativização do impacto da intensificação de informações entre jovens. Por um lado, algumas jovens têm dificuldade de acesso à informação justamente porque a contracepção e a sexualidade é um assunto tabu nas suas famílias e demais grupos sociais. A falta de informação afeta sua percepção do risco de gravidez

4. Nenhum livro consultado (Barros, $200 \mathrm{I}$, Cruz, 1998) faz referência ao preservativo feminino. 
Educação sexual em uma escola...

e reforça o sentimento de que essa questão não lhes diz respeito. Por outro lado, a informação não é por si só suficiente. Mesmo que ela esteja informada sobre a contracepção, o sentimento de "ilegitimidade" de uma mulher jovem cuja sexualidade não é reconhecida em seu meio pode criar obstáculos ao seu acesso à contracepção e afetar negativamente sua prática contraceptiva (Durand, 2002).

Voltando à escola, em sala de aula, a professora deixava claro que o método anticoncepcional mais indicado a jovens era a camisinha, fosse ela a masculina ou a feminina. Apesar de a camisinha feminina ser proclamada como um método que garantiria autonomia à mulher na gestão da sua vida sexual, pois, supostamente, ela não mais dependeria do homem se dispor a usar a camisinha masculina, sua utilização é extremamente limitada pelo seu preço e, de certa forma, pelo seu formato e aparência. Em uma farmácia próxima à escola, uma camisinha feminina custava $R \$ 6,00$, enquanto a masculina, $R \$ 0,80$. O tamanho e o formato da camisinha feminina causavam reação de espanto e risadas por parte de alunas e alunos que, também durante as entrevistas, comentaram nunca a terem visto antes. Diziam que parecia um coador de café e mostravam dificuldades em compreender como ela seria introduzida no corpo. De modo semelhante, o DIU e o diafragma também lhes eram abjetos.

Assim, a camisinha - subentendendo-se camisinha masculina - era constantemente apresentada como o contraceptivo e preservativo ideal para jovens, enquanto a pílula era desaconselhada por não proteger de doenças. Contraditoriamente, uma das questões de prova aplicada à turma tratava de saber qual o método anticoncepcional mais eficiente. Diversos estudantes responderam que era a camisinha, no entanto, essa resposta foi considerada incorreta, pois estatisticamente a pílula anticoncepcional é o método de anticoncepção mais eficaz. A resposta poderia ter sido considerada correta levando em conta o ensinado em sala de aula e a própria ambiguidade da pergunta que não explicitava adequadamente a noção de eficiência.

Além de não proteger de doenças, a pílula era desaconselhada por causa da ingestão de doses diárias de hormônios. Além da professora, o livro associava seu uso a efeitos colaterais: "Ocasionalmente, as pílulas provocam efeitos colaterais, como náuseas, aumento de peso, dores de cabeça; também não se conhecem ao certo os efeitos da pílula a longo prazo" (Silva Junior, Sasson, Sanchez, 1997, p. 199). Esses efeitos colaterais seriam ainda maiores 
entre adolescentes por estarem em fase de crescimento ou passando por mudanças decorrentes da puberdade. Numa sociedade em que o padrão de beleza é um corpo extremamente magro, há de se considerar que a ideia de que a pílula possa resultar em aumento de peso corporal representa um forte limitador ao seu uso, talvez ainda mais intenso entre jovens.

De modo semelhante, Elaine Brandão (2004) observou em sua pesquisa que entre mulheres mais jovens, diferentemente daquelas com mais idade, a pílula não se reveste do espírito de contestação e de liberdade, próprios do contexto dos anos 1960 e 1970, no qual ela emergiu. Segundo a pesquisadora, sobressai hoje uma visão da pílula como algo que faz mal à saúde, que engorda ou deforma o corpo.

Cabe observar que esse discurso escolar é absolutamente distinto do que divulgam atualmente os ginecologistas e os laboratórios farmacêuticos. Ressaltam justamente o contrário: os efeitos benéficos das pílulas que não resultariam em ganho de peso, mas ajudariam a regular o ciclo menstrual, trariam melhorias na pele e no cabelo, preveniriam alguns tipos de câncer, entre outros (Schering, 2004, 2004a).

Além disso, o uso diário da pílula oral pressupõe, mesmo que indiretamente, uma relação estável ou, no mínimo, uma vida sexual com certa periodicidade. Parece não fazer muito sentido ingerir doses diárias de hormônios, temendo o ganho de peso, entre possíveis outros efeitos colaterais, e ter relações sexuais esporádicas.

Outra questão é que o fato dos métodos anticoncepcionais terem sido minuciosamente explicados em sala de aula não significa que os/as estudantes dominassem seu funcionamento. Ao contrário, expressavam diversas dúvidas a esse respeito. A periodicidade com a qual deveriam ingerir a pílula era motivo de incertezas e alguns/mas continuavam achando que ela só deveria ser ingerida no dia em que a mulher tivesse relação sexual. Essa dúvida surgiu durante as aulas e foi esclarecida pela professora, mas reapareceu durante entrevistas, com meninas e meninos que já tinham estudado esse conteúdo em aula. Outras formas hormonais de anticoncepção - injeções, cápsulas e anel vaginal - foram mencionadas em aula pela professora, no entanto, o fato de não constarem do livro didático dificultava sua assimilação pelos estudantes. A chamada "pílula do dia seguinte" ou "pílula de emergência" nunca foi mencionada.

Outros métodos como DIU, diafragma e a própria camisinha feminina Ihes eram de difícil compreensão. Frequentemente confundiam o DIU com o 
Educação sexual em uma escola...

diafragma e demonstravam não compreender muito bem como esses objetos seriam introduzidos no corpo humano: "É possível fazer xixi usando o DIU ou o diafragma?"; "Como o médico coloca o DIU no corpo da mulher?"5; "O que acontece se o pênis tocar no fiozinho do DIU?"; "Se a vagina tem 12 centímetros, como enfiar com o dedo o diafragma lá dentro?". Estes são exemplos de dúvidas que pareciam não querer calar.

Nota-se que, ainda que soubessem citar os nomes de vários métodos, nem sempre dominavam sua técnica de uso. Não são, portanto, informações pontuais, fornecidas apenas num curto momento da trajetória escolar que garantem a sua assimilação. Nesse aspecto, esse ensino talvez não se diferencie de outros, como Matemática ou Português, por exemplo, quando um mesmo conteúdo é repetido e retrabalhado de um ano a outro. Há de se considerar ainda a distância dessas questões da vida de grande parte dos adolescentes que assistiam àquelas aulas, uma vez que ainda não tinham ingressado na sexualidade adulta (Bozon, 2004), ou seja, ainda não utilizavam esses recursos.

A imprecisão das informações assimiladas sobre o uso de métodos contraceptivos entre adolescentes foi também apontada por outras pesquisadoras (Cabral, 2002, Costa, 2001). Segundo Afonso (1997)' é frequente os jovens saberem citar os nomes de métodos contraceptivos ou de DST, sem que tenham conhecimento mais aprofundado ou saibam explicar seu funcionamento. Em sua investigação, quando a solicitação de informação se restringia a um nível superficial (apenas citar métodos contraceptivos), não havia diferenças significativas entre níveis socioeconômicos e sim entre os sexos. As mulheres apresentaram maior percentual de informação sobre assuntos concernentes à gravidez e métodos contraceptivos, enquanto os homens conheciam mais as DST. Porém, quando a informação exigia maior complexidade (explicar os métodos), as diferenças se revelaram significativas entre os níveis socioeconômicos e tendiam a desaparecer para os sexos. Nesse caso, pessoas de níveis socioeconômicos mais baixos apresentaram um índice maior de desinformação.

5. Essa dúvida parece se intensificar porque o DIU mostrado em sala de aula permanecia dentro de seu invólucro, junto com o aplicador, parecendo ainda maior do que de fato é.

6. Essa pesquisa foi realizada mediante survey, aplicado a 387 estudantes de 14 a 20 anos em escolas públicas e particulares de Belo Horizonte. 
Cabe, por fim, ressaltar o caráter processual do aprendizado e do domínio da contracepção na adolescência, não devendo tomá-los como um percurso linear, dotado de racionalidade que se manifestaria de modo incondicional. O domínio da contracepção inscreve-se em um processo de aprendizado e de tomada de decisões - individual e a dois - no qual o conhecimento dos métodos não é o único elemento decisivo (Brandão, 2004).

\section{CONSIDERAÇÕES FINAIS}

O livro didático destinado às $7^{\mathrm{a}}$ séries do ensino fundamental tem como tema o corpo humano, sendo uma de suas unidades referente à reprodução. $O$ ensino dessa unidade é o principal momento em que a educação sexual se insere concretamente na escola. Ser desenvolvida a partir de um livro de Ciências, dentro dessa disciplina e por seus docentes imprime marcas no modo pelo qual esse trabalho é realizado. O corpo humano é concebido como um organismo, vale dizer, é descrito em sua hierarquia funcional, em que cada um dos órgãos é estudado tendo como foco principal a função reprodutiva. De um modo geral, a gravidez era estudada sob essa perspectiva.

Parece, no entanto, haver uma contradição no trabalho desenvolvido pela escola. Na medida em que a educação sexual é trabalhada a partir do tema reprodução, esta acaba sendo enfatizada, quando é justamente a ocorrência dela entre adolescentes que diversas políticas públicas querem evitar. A relação sexual acaba constantemente vinculada à reprodução - nem que seja para evitá-la - e não ao prazer, às relações entre pessoas, independentemente da sua orientação sexual etc.

Outra questão é que, no livro didático, os métodos anticoncepcionais são recomendados a pessoas adultas que optariam pelo planejamento familiar, de modo que os filhos tivessem suas necessidades básicas atendidas. A vinculação dos métodos anticoncepcionais aos adultos os distancia dos adolescentes, para quem é apenas recomendado o preservativo. Este acaba praticamente limitado ao preservativo masculino, devido aos altos custos da camisinha feminina e à sua baixa aceitação entre adolescentes, seja pelo seu tamanho e aspecto físico, seja pela dificuldade em compreender como utilizá-la. Desse modo, apesar de o corpo da mulher ser priorizado na educação sexual escolar e de a mulher estar socialmente mais investida do que o homem da responsabilidade por 
Educação sexual em uma escola...

evitar a gravidez, acaba dependendo do homem, em última instância, a decisão e a adoção do preservativo, pois é no seu corpo que a camisinha masculina precisa ser inserida.

Uma das principais preocupações da educação sexual refere-se à gravidez na adolescência. Esse tema ganha atualmente privilegiado destaque se comparado à Aids, por exemplo. Ao contrário do NAM, nas aulas ela foi rapidamente mencionada junto com outras DST e para justificar o uso de preservativos. Esse é um ponto que merece atenção e cuidado, pois talvez, diante de maior controle dessa epidemia no Brasil e da disponibilidade de medicamentos para controlá-la, esse assunto esteja ganhando menos atenção nas intervenções educacionais. Outras pesquisas são necessárias para constatar se isto é algo constante ou uma particularidade daquele ano letivo na escola pesquisada.

Já a gravidez na adolescência era foco de apurada atenção também nessa escola, a ponto de um garoto concluir que ali aprendera que, além de gravidez, existe "gravidez precoce". Diferentemente de outros momentos históricos, a gravidez nesta faixa etária aparece atualmente como um anacronismo, pois demandas sociais e econômicas produzem a concepção de que essas duas experiências mantêm uma relação de inadequação: a adolescência é concebida como um período de formação e de divertimento, enquanto a gravidez requer amadurecimento, planejamento e estrutura econômicos, profissionais e pessoais para criar um novo ser.

Apesar do destaque dado à gravidez em relação à Aids, o preservativo permanece sendo o método anticoncepcional e de proteção mais recomendado, enquanto a pílula anticoncepcional é desaconselhada. A pílula, no entanto, é extremamente eficiente na prevenção da gravidez, e seus efeitos colaterais negativos, tão enfatizados na escola, têm sido descartados por médicos e indústrias farmacêuticas. Apesar da importância de se questionar esse discurso da área médica, cabe problematizar se o tratamento dado à pílula na escola tem sido útil aos adolescentes. Para isso, deve-se considerar, conforme apontado por várias pesquisas, que a camisinha acaba frequentemente sendo abandonada dentro de relações estáveis. Quando isso ocorre, a pílula não entra como substitutivo, entre outros motivos, pelo desprestígio social.

Para além de aprender as etapas de uma gestação e os modos de prevenila, aprende-se na escola que uma gravidez deve ser planejada, de modo a ocorrer no momento certo e dentro de uma relação estável entre um homem e uma mulher. Relações homossexuais não são discutidas. 
Acaba-se, desse modo, criando-se ideais de relação sobre as quais a escola intervém. Exemplo disso é a apresentação no livro didático dos métodos anticoncepcionais, que devem ser usados por um casal que deseje e planeje o número de filhos e o momento de tê-los. $\bigcirc$ uso do preservativo, tão divulgado nessas aulas, também acaba sendo recomendado para um casal de namorados com uma relação duradoura, pois é nesse tipo de relacionamento que uma relação sexual teria legitimidade.

Essa é uma questão importante. Conforme apontam também outras pesquisas, não reconhecer a sexualidade adolescente pode estar distanciando esses jovens do uso de preservativos ou de métodos anticoncepcionais. Sem o reconhecimento social - e escolar - das diversas formas de os adolescentes relacionarem-se sexualmente, a transmissão de informações pode ter um impacto limitado em suas vidas. A não-legitimidade de determinadas formas de relação, como a entre dois "ficantes" ou entre homossexuais, pode dificultar o acesso à informação e a preservativos, assim como intervir negativamente na sua utilização.

Apesar de receberem informações detalhadas sobre como os métodos anticoncepcionais e de prevenção devem ser utilizados, os jovens nem sempre assimilam essas informações, e dúvidas permanecem após essas aulas. Decorre disso a necessidade de que esses ensinamentos sejam retomados noutros momentos das suas trajetórias escolares. Parece também importante ampliar o leque de informações, incluindo, no livro didático e nas aulas, mais informações sobre pílulas anticoncepcionais injetáveis, cápsulas, anéis vaginais e a própria "pílula do dia seguinte", além de informações sobre locais em que podem ser adquiridos, como postos de saúde, criando-se assim opções diversificadas e formas de acesso.

\section{REFERÊNCIAS BIBLIOGRÁFICAS}

AFONSO, M. L. M. A Polêmica sobre adolescência e sexualidade. Belo Horizonte, 1997. Tese (dout.) Faculdade de Educação, Universidade Federal de Minas Gerais.

ALTMANN, H. Pedagogias da sexualidade e do gênero: educação sexual em uma escola. Tese (dout.) Programa de Pós-Graduação da Pontifícia Universidade Católica do Rio de Janeiro, 2005.

AMBIENTE EM REDE: Informativo do projeto Educação Ambiental e Saúde. A. 2, n.3, Rio de Janeiro: SME, jul./ago. 2002. 
Educação sexual em uma escola...

BAJOS, N.; FERRAND, M. (orgs.) De la contraception à l'avortement: sociologie des grossesses non prévues. Paris: Inserm, 2002.

BAJOS, N, FERRAND, M.; HASSAUN, D. Au risque de l'echec: la contraception au quotidien. In: BAJOS, N.; FERRAND, M. (orgs.) De la contraception à l'avortement: sociologie des grossesses non prévues. Paris: Inserm, 2002. p.33-78.

BARROS, C. O Corpo humano: $7^{a}$ série. São Paulo: Ática, 2001.

BEGUOCl, L. Governo federal anuncia anticoncepcional a R\$ 0,40. Folha de S. Paulo, 28 maio 2007. Disponível em: http://www l.folha.uol.com.br/fsp/cotidian/ff290520070 I.htm. Acesso em: 28 maio 2007.

BERQUÓ, E. CAVENAGUI, S. Mapeamento sócio-econômico e demográfico dos regimes de fecundidade no Brasil e sua variação entre 199| e 2000. In: ENCONTRO NACIONAL DE ESTUDOS POPULACIONAIS, ABEP, I4. Anais eletrônicos. Caxambu, 2004. Disponível em: www.abep.nepo.unicamp.br/site_eventos_abep/PDF/ABEP. Acesso em: 25 set. 2004.

BERTANI, M. Sur la généalogie du bio-povoir. In: ZANCARINI, J. (orgs.) Lectures de Michel Foucault. Paris: ENS Editions, 200I. p. 15-36.

BOZON, M. A Nova normatividade das condutas sexuais ou a dificuldade de dar coerência a experiências íntimas. In: HEILBORN, M. L. (org.) Família e sexualidade. Rio de Janeiro: FGV, 2004. p. I 19-153. (Col. Família, geração e cultura)

BRANDÃO, E. R. Iniciação sexual e afetiva: exercício da autonomia juvenil. In: HEILBORN, M. L. (org.) Família e sexualidade. Rio de Janeiro: FGV, 2004. p.63-86. (Col. Família, geração e cultura)

BRASIL. Secretaria da Educação Fundamental. Parâmetros Curriculares Nacionais: terceiro e quarto ciclos: apresentação dos temas transversais. Brasília, 1998.

CABRAL, C. da S. Novos pais, jovens pais: vicissitudes da paternidade entre jovens de uma comunidade favelada do município do Rio de Janeiro. Rio de Janeiro, 2002. Dissert. (mestr.) Instituto de Medicina Social, Universidade Estadual do Rio de Janeiro.

COSTA, T. Histórias que merecem ser ouvidas e contadas: uma abordagem da gravidez em adolescentes de 10 a 14 anos. Rio de Janeiro, 200 I. Dissert. (mestr.) Instituto de Medicina Social, Universidade Estadual do Rio de Janeiro.

CRUZ, D. O Corpo humano. São Paulo: Ática, 1998. (Col. Ciências e educação ambiental)

DURAND, S. Accès à la contraception et recours à l'IVG chez les jeunes femmes. In: BAJOS, N.; FERRAND, M. (orgs.) De la contraception à l'avortement: sociologie des grossesses non prévues. Paris: Inserm, 2002. p.249-302. 
FELIPE, J. Sexualidade nos livros infantis: relações de gênero e outras implicações. MEYER, D. (org.) Saúde e sexualidade na escola. Porto Alegre: Mediação, 1998. p. I I I I 24.

FOUCAULT, M. A História da sexualidade, I: A vontade de saber. 12. ed. Rio de Janeiro: Graal, 1997. (Trad. Maria Thereza da Costa Albuquerque e J.A. Guilhon Albuquerque)

Dits et écrits. Paris: Gallimard, 1994. La Politique de la santé au XVIII' siècle : 1954-1988. p.13-27.

GALLAND, O. Adolescence, post-adolescence, jeunesse: retour sur quelques interprétations. Revue Française de Sociologie. Paris, n.42, v.4, p.6I I-640, oct./dez., 2001 .

Les jeunes. 5. ed. Paris: La Découverte, 1996.

HEILBORN, M. L. et al. Aproximações socioantropológicas sobre a gravidez na adolescência. Horizontes Antropológicos, Porto Alegre, v.8, n. I7, p. I3-44, jun. 2002.

IBGE. Censo demográfico 1980-2000, tabela 2: taxas específicas de fecundidade, segundo as grandes regiões e grupos de idade das mulheres - 1980/2000, 2002. Disponível em www. ibge.gov.br. Acesso em: 2 set. 2002.

Censo demográfico 1940-2000, tabela I: taxas de fecundidade total, segundo as grandes regiões - 1940/2000, 2002a. Disponível em www.ibge.gov.br. Acesso em: 2 set. 2002.

LE VAN, C. Les Grossesses à l'adolescence: normes sociales, réalités vécues. Paris: Harmattan, 1998.

ROSISTOLATO, R. Orientação sexual com "jeitinho brasileiro": uma análise antropológica da intervenção escolar na socialização afetivo-sexual dos adolescentes. Rio de Janeiro, 2007. Tese (dout.) Programa de Pós-Graduação em Sociologia e Antropologia, Universidade Federal do Rio de Janeiro.

SCHERING. Alta eficacia anticonceptiva para a mujer joven. Santiago do Chile, 2004. (Prospecto)

SCHERING. ¿Quién dice que no existe un anticonceptivo oral con una excelente tolerancia y beneficios adicionales? Santiago do Chile, 2004a. (Prospecto)

SILVA JUNIOR, C. da; SASSON, S.; SANCHEZ, P. S. B. Ciências: entendendo a natureza: o homem no ambiente. São Paulo: Saraiva, 1997. (Livro do professor)

Recebido em: junho 2007

Aprovado para publicação em: fevereiro 2008 